\title{
Fracture rates and risk factors for fractures in patients with spinal cord injury
}

\author{
P Vestergaard $^{1}, \mathrm{~K}_{\mathrm{Krogh}^{2}}$, L Rejnmark ${ }^{1}$ and L Mosekilde ${ }^{1}$ \\ ${ }^{1}$ Aarhus Bone and Mineral Research Group, Department of Endocrinology and Metabolism, ${ }^{2}$ Surgical Research Unit, \\ Department of Surgery L Aarhus Amtssygehus, DK-8000 Aarhus C, Denmark
}

\begin{abstract}
Aim: To study fracture rates and risk factors for fractures in patients with spinal cord injuries.
Material and methods: A self-administered questionnaire was mailed to 646 members of the Danish Paraplegic Association and 1000 randomly selected normal controls. 438 patients (309 males, 129 females, 67.8\%) and 654 controls (332 males, 322 females, 65.4\%) returned the questionnaire. Median age in patients was 42 , range $10-80$ years, and in controls 43 , range $19-$ 93 years $(2 \mathrm{p}=0.25)$.

Results: The crude fracture rate was $2 \%$ per year in patients and $1 \%$ per year in controls $(\mathrm{RR}=2.0, P<0.001)$. Low-energy fractures were much more prominent in patients $(19.0 \%$ of all fractures) than in controls $(1.4 \%, P<0.001)$. The fracture rate did not differ before the injury but increased after the injury to a constant level from the third year and forward. Fractures of the lower extremities were more prominent in patients than controls (femurs: $R R=23.4$, $P<0.001$, lower legs: $\mathrm{RR}=5.2, P<0.001$, feet/toes: $\mathrm{RR}=2.4, P=0.006)$ while fractures of the forearms $(P<0.001)$ and clavicles $(P=0.03)$ were absent among patients. Fractures were more frequent in female patients $(\mathrm{RR}=1.6, P=0.008)$ and in male patients with a family history of fractures $(\mathrm{RR}=2.0, P=0.004)$.

Conclusions: Low-energy fractures especially of the lower extremities are frequent in spinal cord injury patients and especially among female patients. The forearms seem protected from fractures.
\end{abstract}

Keywords: spinal cord injury; fracture; incidence; risk factor; paraplegia

\section{Introduction}

It has long been recognised that immobilisation leads to a loss of bone mineral. ${ }^{1-5}$

However, studies on fracture rates in patients with spinal cord injury (SCI) have been scarce ${ }^{6-10}$ and often in case report form. ${ }^{11-13}$ Most studies only reported cross-sectional data on the percentage of patients having sustained one or more previous fractures ${ }^{6,7,9,10}$ - in some cases without stating the time interval between the SCI and the actual study. ${ }^{6}$ Furthermore, the fracture rates in patients were not compared with a control group ${ }^{6,7,9,10}$ Frisbie et $a l^{8}$ only studied males and did not use a regular control group but compared fracture occurrence in patients with data from population registers.

In particular, previous studies have reported an increased occurrence of low energy fractures of the lower limbs especially of the femora ${ }^{6-10,14,15}$ in SCI patients, many of the fractures being the results of falls from wheelchairs. ${ }^{16}$ Reports on fractures in parts of the skeleton other than the lower limbs have been scarce $^{15}$ and have not been subject to statistical testing.

Correspondence: P Vestergaard, The Osteoporosis Clinic, Aarhus Amtssygehus Tage Hansens Gade 2, DK-8000 Aarhus C, Denmark
The aim of the present study was to evaluate fracture rates in all parts of the skeleton in a broad age group of both male and female SCI patients and to study risk factors for fractures in SCI patients.

\section{Materials and methods}

A self-administered questionnaire was mailed to 646 members of the Danish Paraplegic Association and to 1000 control subjects randomly selected from the background population. After 6 weeks the questionnaire was reissued to non-respondents. The project was approved by the regional ethical committee (J.nr. 1997/ 3904).

The questionnaire contained questions about: (1) age in years; (2) gender (male/female); (3) smoking habits (current smoker/previous smoker/never-smoker); (4) use of corticosteroids (ever-use/never use, and in case of ever use age at first treatment and total treatment duration in years); (5) occurrence of fractures in parents or siblings (yes/no/do not know); (6) diagnosis of 'osteoporosis' in parents or siblings (yes/no/do not know); (7) previously diagnosed 
'osteoporosis' in the participant - yes/no/do not know); (8) previous fractures (yes/no). In case of fractures the participant was asked to state which bone(s) had fractured, what had caused the fracture (eg fall, automobile accident etc.), whether or not he or she had been operated upon for the fracture, whether or not he or she had been treated with plaster of Paris, and finally whether the fracture had been treated on an inpatient or outpatient basis.

Female participants were asked whether they were pre- or postmenopausal and if they were postmenopausal at approximately what age the menopause had begun and whether or not they had used oestrogen compounds after the menopause. In case of use they were asked at what age use had started and for how many years they had used oestrogens. Furthermore, female participants were asked, if they had ever used oral contraceptives (OCs). In case of use they were asked at what age they first used OCs and the total duration of use in years. Male participants were asked whether they had previously used male sex steroids.

SCI patients were asked to state at which age the SCI was sustained or if the SCI was congenital, the level of injury (cervical, thoracic or lumbar based upon the highest affected motor region), the function level (total or partial paralysis of limbs below the injury), their best level of function (walks without crutches or other support, walks using crutches or other support, uses an electric-powered wheel-chair, uses a manual wheel-chair or unable to use any of the earlier mentioned), their level of out-door activities (outdoor activities every day, one or more times per week, less than once per week or never undertaking outdoor activities), present use of standing device or not, whether or not they worked (and if yes state the number of hours per week), whether or not they were involved in sports activities (and if yes to state the number of hours per week) and whether they were afraid of sustaining fractures (yes/no/do not know).

The energy at which the fracture had emerged was subdivided into: (1) low-energy fractures (also called fragility fractures, i.e. fractures occurring after minor or no trauma); (2) medium-energy fractures (ie fractures occurring after falls at the same level, dropping medium weight objects onto/squeezing fingers or toes etc.); and (3) high-energy trauma (ie fractures occurring after falls from one level to another, car accidents etc.).

The location of the fractures was subdivided as follows: (1) fractures of skull or jaws; (2) fractures of spine; (3) fractures of upper extremities (forearm or upper arm); (4) fractures of hands or fingers; (5) fractures of the femora; (6) fractures of lower legs (tibia or fibula incl. ankle fractures); (7) fractures of feet or toes; (8) fracture of clavicles; and (9) other fractures (ribs, pelvis etc.).

If more than one fracture occurred at the same time the largest bone that fractured was counted as the fractured bone. Incidence rates were calculated for fracture episodes (ie multiple fractures at the same time counted as one fracture episode). Fractures occurring at the same time as the spinal cord injury were not included in the analysis.

Incidence rates were compared by relative risks and statistical comparisons were made using MantelHaenszel type $\chi^{2}$ statistics. Numbers were compared by $\chi^{2}$ for contingency tables, Fisher's exact test or Mann - Whitney statistics when appropriate. MantelHaenszel statistics were used to compare fracture occurrence in groups. A Cox proportional hazard regression analysis with gender and age at SCI as independent variables was performed to test the effect of age at SCI on the time until first fracture episode.

\section{Results}

A total of 438 SCI patients $(67.8 \%)$ and 654 normal controls $(65.4 \%, P=0.34)$ returned the questionnaire. Among the SCI patients there were 129 females and 309 males and among the normal control there were 322 females and 332 males. Tables 1 and 2 shows the distribution of baseline characteristics among patients and controls. The male controls were somewhat older than the female respondents (median 46 years, range $20-93$ years vs 40 years, range $19-91,2 P<0.001)$ and the male SCI patients (median 43 years, range $17-80$ years, $2 P=0.004)$ - data not shown. The higher frequency of corticosteroid use among SCI patients (Table 1) was related to administration to patients suffering traumatic lesions immediately after the injury. Male SCI patients had a borderline significantly higher frequency of osteoporosis among parents or siblings than normal males (13 vs 6 in normal controls, $P=0.04)$. Otherwise there were no gender differences. Only three males among both SCI patients and normal controls ever reported use of male sex hormones $(2 \mathrm{p}=1.00)$. Among the SCI patients congenital SCI tended to be more frequent in females $(2 p=0.04)$ while males used more time at work and on sports activities (Table 2). Female patients tended to be more afraid of fractures (Table 2).

After the SCI a total of 126 fractures were observed during 6376 years of observation time. Before the SCI 110 fractures were observed during 11409 years of observation time. The cumulated incidence proportion with fractures was $21.1 \%(95 \% \mathrm{CI}: 17.3-25.3)$. The normal controls sustained 287 fractures during 28585 years of observation time. In SCI the overall fracture rate $(2 \% / y r)$ was higher than in the normal population $(1 \% / \mathrm{yr}, \mathrm{RR}=2.0, P<0.001)$. The fracture rate was equal to the normal controls before the SCI occurred, but increased to remain stable from the 3rd year and onward after the SCI (Figure 1).

Table 3 shows that low-energy fractures dominated among SCI patients while high-energy fractures were rare. There was no difference between male and female SCI patients in the distribution of fracture energies $(P=0.19)$. Table 4 shows that fractures of the femora, lower legs and the feet were highly 
Table 1 Baseline characteristics

\begin{tabular}{|c|c|c|c|}
\hline Variable & SCI patients $(\mathrm{n}=438)$ & Normal controls $(\mathrm{n}=654)$ & $\mathrm{P}$ \\
\hline Age (median, range) & $42(10-80)$ years & $43(19-93)$ years & $0.25^{\mathrm{b}}$ \\
\hline Smoking & & & $0.14^{\mathrm{a}}$ \\
\hline Never smoker & $147(34 \%)$ & $254(40 \%)$ & \\
\hline Current smoker & $161(37 \%)$ & $216(34 \%)$ & \\
\hline Previous smoker & $128(29 \%)$ & $170(27 \%)$ & \\
\hline Ever use of coritcosteroids & & & $0.02^{\mathrm{a}}$ \\
\hline Yes & $40(9 \%)$ & $36(6 \%)$ & \\
\hline No & $391(91 \%)$ & $599(94 \%)$ & \\
\hline Age at first use of corticosteroids & $37(9-78)$ years & $35(11-75)$ years & $0.66^{\mathrm{b}}$ \\
\hline Duration of corticosteroid use & & & $0.19^{\mathrm{c}}$ \\
\hline$<1$ year & $26(65 \%)$ & $16(47 \%)$ & \\
\hline$>1$ year & $14(35 \%)$ & $18(53 \%)$ & \\
\hline Ever diagnosed with osteoporosis & & & $0.12^{\mathrm{a}}$ \\
\hline Yes & $9(2 \%)$ & $6(1 \%)$ & \\
\hline No & $416(98 \%)$ & $619(99 \%)$ & \\
\hline Family history of osteoporosis & & & $0.16^{\mathrm{a}}$ \\
\hline No & $376(86 \%)$ & $545(83 \%)$ & \\
\hline Yes & $20(5 \%)$ & $24(4 \%)$ & \\
\hline Do not know & $41(9 \%)$ & $85(13 \%)$ & \\
\hline Family history of fractures & & & $<0.001^{\mathrm{a}}$ \\
\hline No & $283(65 \%)$ & $347(53 \%)$ & \\
\hline Yes & $100(23 \%)$ & $229(35 \%)$ & \\
\hline Do not know & $54(12 \%)$ & $78(12 \%)$ & \\
\hline Ever use of oral contraceptives* & & & $0.10^{\mathrm{a}}$ \\
\hline Yes & $82(65 \%)$ & $230(73 \%)$ & \\
\hline No & $45(35 \%)$ & $87(27 \%)$ & \\
\hline Age of first use of oral contraceptives* & $19(13-40)$ years & $18(13-46)$ years & $0.96^{\mathrm{b}}$ \\
\hline Duration of oral contraceptive use* & & & $0.88^{\mathrm{c}}$ \\
\hline$<5$ years & $40(49 \%)$ & $108(48 \%)$ & \\
\hline$>5$ years & $41(51 \%)$ & $119(52 \%)$ & \\
\hline Premenopausal* & $94(73 \%)$ & $228(72 \%)$ & $0.84^{\mathrm{a}}$ \\
\hline Postmenopausal* & $35(27 \%)$ & $90(28 \%)$ & \\
\hline Age at menopause in years* & $48(30-58)$ years & $47(30-55)$ years & $0.22^{\mathrm{b}}$ \\
\hline Use of HRT after menopause* & & & $0.27^{\mathrm{a}}$ \\
\hline Yes & $17(46 \%)$ & $32(36 \%)$ & \\
\hline No & $20(54 \%)$ & $58(64 \%)$ & \\
\hline Age at first HRT use in years* & $48(40-60)$ years & $47(32-55)$ years & $0.22^{\mathrm{b}}$ \\
\hline Duration of HRT use* & & & $1.00^{\mathrm{c}}$ \\
\hline$<5$ years & $8(50 \%)$ & $16(52 \%)$ & \\
\hline$>5$ years & $8(50 \%)$ & $15(48 \%)$ & \\
\hline
\end{tabular}

HRT: Hormonal replacement therapy, *: only female respondents. ${ }^{\mathrm{a}} \chi^{2}$ for contingency tables (p), ${ }^{\mathrm{b}} \mathrm{Mann}-\mathrm{Whitney}$ test $(2 \mathrm{p})$,

${ }^{\mathrm{c}}$ Fisher's exact test $(2 \mathrm{p})$

increased among patients compared to controls, while fractures of the forearms and clavicles were absent among patients.

Table 5 shows the impact of risk factors on fracture rates in the two genders. Females had more fractures than males $(\mathrm{RR}=1.6, P=0.008)$. However, no single fracture type was more frequent in female than in male SCI patients. None of the risk factors showed a uniform link to any of the genders. Male patients with a family history of fracture had more fractures than without such a history $(\mathrm{RR}=2.0, P=0.004)$ and also male patients with lumbar lesions had more fractures than males with cervical lesions $(\mathrm{RR}=2.4, P<0.001)$. Female patients undertaking daily outdoor activities had fewer fractures than females being less outdoors $(\mathrm{RR}=0.4, P 0.005)$ and female patients using wheel- chairs had fewer fractures than female patients who could walk as best performance $(\mathrm{RR}=0.4, P=0.003)$.

In a Cox analysis there was no effect of age at SCI upon time until first fracture episode $(\mathrm{RR}=1.0$, $P=0.22)$ while fractures were more frequent in women $(\mathrm{RR}=1.6, P=0.048)$.

\section{Discussion}

In the present study we have shown that fractures were frequent events in spinal cord injury patients, especially as low-energy fractures of the lower extremities. Fractures of the forearms were rare [probably due to a combination of two factors: patients using manual wheelchairs are protected from bone loss in the forearms and patients with tetraplegia are unable to 
Table 2 Characteristics of SCI patients

\begin{tabular}{|c|c|c|c|}
\hline Characteristic & Females $(\mathrm{n}=1290)$ & Males $(\mathrm{n}=309)$ & $\mathrm{P}$ \\
\hline Age in years (median, range) & $40(10-78)$ & $43(17-80)$ & $0.77^{\mathrm{b}}$ \\
\hline Age at SCI in years (median, range) & $27(0-64)$ & $24(0-69)$ & $0.55^{\mathrm{b}}$ \\
\hline Time since injury in years (median, range) & $11(0-59)$ & $13(1-61)$ & $0.23^{\mathrm{b}}$ \\
\hline Injury & & & $0.09^{\mathrm{a}}$ \\
\hline Cervical & $51(40 \%)$ & $147(49 \%)$ & \\
\hline Complete paralysis of arms of legs & $2(4 \%)$ & $10(7 \%)$ & $0.10^{\mathrm{a}}$ \\
\hline Partial paralysis of arms, total paralysis of legs & $34(68 \%)$ & $111(78 \%)$ & \\
\hline Partial paralysis of arms and legs & $14(28 \%)$ & $21(15 \%)$ & \\
\hline Thoracic & $41(32 \%)$ & $98(33 \%)$ & \\
\hline Complete paralysis of legs & $27(69 \%)$ & $69(79 \%)$ & $0.22^{\mathrm{a}}$ \\
\hline Partial paralysis of legs & $12(31 \%)$ & $18(21 \%)$ & \\
\hline Lumbar & $35(28 \%)$ & $56(19 \%)$ & \\
\hline Complete paralysis of legs & $15(45 \%)$ & $31(57 \%)$ & $0.28^{\mathrm{a}}$ \\
\hline Partial paralysis of legs & $18(55 \%)$ & $23(43 \%)$ & \\
\hline Congenital SCI & $7(6 \%)$ & $4(1 \%)$ & $0.04^{\mathrm{c}}$ \\
\hline Acquired SCI & $117(94 \%)$ & $295(99 \%)$ & \\
\hline Outdoor activities & & & $0.04^{\mathrm{a}}$ \\
\hline Every day & $100(78 \%)$ & $268(88 \%)$ & \\
\hline At least once a week & $23(18 \%)$ & $29(9 \%)$ & \\
\hline Less than once a week & $5(4 \%)$ & $9(3 \%)$ & \\
\hline Best daily activity level & & & $0.38^{\mathrm{a}}$ \\
\hline Walks without crutches or other support & $5(4 \%)$ & $9(3 \%)$ & \\
\hline Walks with crutches or other support & $23(18 \%)$ & $41(14 \%)$ & \\
\hline Uses a wheelchair & $98(78 \%)$ & $252(83 \%)$ & \\
\hline Manual & $83(86 \%)$ & $199(80 \%)$ & $0.22^{\mathrm{a}}$ \\
\hline Electric-powered & $14(14 \%)$ & $50(20 \%)$ & \\
\hline Work & & & $0.05^{\mathrm{a}}$ \\
\hline Yes & $39(30 \%)$ & $124(40 \%)$ & \\
\hline No & $90(70 \%)$ & $183(60 \%)$ & \\
\hline Hours of work per week (median and range)* & $19.75(2-37)$ & $31(3-70)$ & $0.003^{\mathrm{b}}$ \\
\hline Current use of standing device & & & $0.81^{\mathrm{a}}$ \\
\hline Yes & $42(35 \%)$ & $99(34 \%)$ & \\
\hline No & $78(65 \%)$ & $194(66 \%)$ & \\
\hline Sports activities & & & $0.45^{\mathrm{a}}$ \\
\hline Yes & $54(42 \%)$ & $118(38 \%)$ & \\
\hline No & $74(58 \%)$ & $190(62 \%)$ & \\
\hline Hours of sport per week (median and range)* & $2(0.5-13)$ & $3.5(0.5-15)$ & $0.002^{\mathrm{b}}$ \\
\hline Fear of fractures & & & $0.003^{\mathrm{a}}$ \\
\hline No & $46(36 \%)$ & $154(51 \%)$ & \\
\hline Yes & $53(41 \%)$ & $78(26 \%)$ & \\
\hline Do not know & $30(23 \%)$ & $70(23 \%)$ & \\
\hline
\end{tabular}

${ }^{\mathrm{a}} \chi^{2}$ for contingency tables $(\mathrm{p}),{ }^{\mathrm{b}}$ Mann-Whitney test $(2 \mathrm{p}),{ }^{\mathrm{c}}$ Fisher's exact test $(2 \mathrm{p})$. Due to missing value sums may not add to 438. *: among those who did work or was involved in sports activities

use their forearms to prevent falls and the traumas which thus affects other parts of the body]. Furthermore the overall frequency of classical fall-related fractures may be lower in SCI patients. The absence of clavicle fractures may likewise be explained as a consequence of the low number of high energy traumas in SCI patients - clavicle fractures often resulting from bicycle or motor vehicle accidents.

No specific factor was consistently associated with fracture risk in both genders. This suggests that the fracture risk was the consequence of bone biomechanical competence loss to such an extent that no other factor by itself could modulate the fracture risk. Therefore no consistent differences were seen with level of outdoor activities, best functional level (wheelchair or walking), involvement in sports activities or being in work or not. Consequently it seems that measures to prevent e.g. falls have to be aimed broadly as no specific daily life factor is particularly involved in fracture genesis. Furthermore, it may be more effective to prevent bone loss by antiresorptive medical treatment.

The borderline significantly lower fracture rate in patients using standing devices is not readily explainable. These patients tend to have higher bone mineral density and thus a higher bone biomechanical competence than patients not performing standing. ${ }^{17}$ On the other hand the patients who do not use standing devices are often more handicapped and are thus less prone to trauma. The observed borderline 
significant difference may be due to the uncertainties stemming from the relatively low number currently using standing devices.

The higher fracture frequency in females needs further investigation. However, it is likely that the higher rate is related to the higher frequency of osteoporosis in women in general. ${ }^{18}$ The association between a family history of fractures and subsequent fractures in the subject has also been observed in other studies. ${ }^{19}$ The fact that it is only observed in the males may be related to social inheritance of behavioural patterns (eg. a larger proneness to trauma); but may

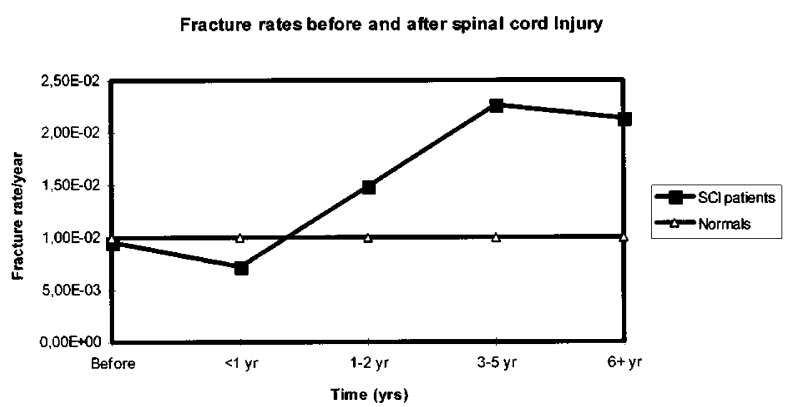

Figure 1 Distribution of crude fracture rates according to time of spinal cord injury. The difference between SCI patients and controls was significant from the third year after the injury and onwards

Table 3 Distribution of fracture energies. Actual number of fractures and $(\%)$

\begin{tabular}{lcc}
\hline Fracture energy & SCI patients & Normal controls \\
\hline Low & $24(19.0)$ & $4(1.4)$ \\
Medium & $86(68.3)$ & $145(52.0)$ \\
High & $16(12.7)$ & $130(46.6)$ \\
\hline
\end{tabular}

$P<0.001$ by $\chi^{2}$ for contingency tables also be related to the fact that fracture rates are so high in SCI patients due to the loss of bone biomechanical competence that other risk factors are masked. This could perhaps also explain the absence of an age effect upon time until first fracture episode.

The rate of fractures was close to that observed in the study by Frisbie. ${ }^{8}$ After a mean of 21 years of observation time we would expect 1 - $(1-$ $0.0175)^{21.1}=31 \%$ males with fractures, where Frisbie ${ }^{8}$ observed $33 \%$ among males. Comarr et $a l^{6}$ reported fractures in $11 \%$ of the study patients but did not state the observation period since SCI. Eichenholtz et $a l^{7}$ reported 4\% fractures without a specific observation time. Ingram et $a l^{9}$ observed $5 \%$ fractures but also did not state the observation time while Ragnarsson and Sell ${ }^{10}$ reported $4 \%$ with fractures, rates being a little higher in females than males $(5.4$ vs $3.5 \%)$. In the data by Ragnarsson and Sell ${ }^{10}$ the mean time from injury to fracture was 9 years but no mean observation time was specified. Ragnarsson and Sell $^{10}$ also found $1.45 \%$ fractures in 3027 patients drawn from the National Spinal Cord Injury Data Research Centre over a 5 year period.

The fact that overall fracture rate before the SCI was not different from the general population is interesting as it could indicate that SCI patients in general are not more prone to fracture producing traumas.

The fact that the frequency of fractures for the first year after the SCI did not differ from the controls could be related to the lower level of activity in the first period of time after the injury. Furthermore, the loss of bone mineral has not yet reached its maximum within the first year from the injury. ${ }^{1}$ Biering-Sørensen et $a l^{1}$ demonstrated that $\mathrm{BMC}$ in the lower extremities decreased after SCI and a new steady state for BMC was reached after 2 years at $40-50 \%$ for proximal tibia and at $60-70 \%$ for the femoral neck. This is in accordance with our observation that the fracture risk remained significantly increased from the third year after SCI and forwards. However, Biering-Sørensen et $a l^{1}$ also found that BMC of the femoral shaft

Table 4 Distribution of fracture types

\begin{tabular}{|c|c|c|c|c|}
\hline Fracture type & $\begin{array}{l}\text { Fracture rates (per } \\
10000 \text { person years) } \\
\text { in SCI patients }\end{array}$ & $\begin{array}{l}\text { Fracture rates (per } \\
10000 \text { person years) } \\
\text { in normal controls }\end{array}$ & $R R(95 \% C I)^{a}$ & $\mathbf{P}^{b}$ \\
\hline Skull \& jaws & 1.6 & 2.5 & $0.6(0.1-5.1)$ & 0.67 \\
\hline Spine & 3.1 & 1.4 & $2.2(0.4-11.7)$ & 0.34 \\
\hline Forearm & 0.0 & 25.9 & $0.0(-)$ & $<0.001$ \\
\hline Upper arm & 7.8 & 11.5 & $0.7(0.3-1.7)$ & 0.42 \\
\hline Fingers/hands & 14.1 & 19.9 & $0.7(0.4-1.4)$ & 0.33 \\
\hline Clavicles & 0.0 & 7.7 & $0.0(-)$ & 0.03 \\
\hline Femur & 73.7 & 3.2 & $23.4(14.4-38.0)$ & $<0.001$ \\
\hline Lower leg & 69.0 & 13.3 & $5.2(3.5-7.7)$ & $<0.001$ \\
\hline Feet/toes & 22.0 & 9.1 & $2.4(1.3-4.5)$ & 0.006 \\
\hline Other & 6.3 & 3.2 & $2.0(0.6-6.3)$ & 0.24 \\
\hline Crude rate & 198.0 & 97.6 & $2.0(1.6-2.5)$ & $<0.001$ \\
\hline
\end{tabular}

${ }^{\mathrm{a}}$ Rate ratio. ${ }^{\mathrm{b}}$ Mantel-Haenszel $P\left(\chi^{2}\right)$ 
Table 5 Relative risks of fracture stratified by gender

\begin{tabular}{|c|c|c|c|c|c|}
\hline Risk factor & $\begin{array}{l}\text { Rate in females } \\
\text { (/10 } 000 \text { years })\end{array}$ & $R R$ in females & $\begin{array}{l}\text { Rate in males } \\
\text { (/10 000 years) }\end{array}$ & $R R$ in males & Common $R R$ \\
\hline Outdoor activities & & $0.4(0.005)$ & & $1.2(0.67)$ & $0.7(0.12)$ \\
\hline Every day & 220 & & 181 & & \\
\hline Not every day & 495 & & 156 & & \\
\hline Work & & $0.6(0.18)$ & & $1.2(0.49)$ & $1.0(0.80)$ \\
\hline Yes & 202 & & 186 & & \\
\hline No & 320 & & 159 & & \\
\hline Family history of fractures & & $1.1(0.79)$ & & $2.0(0.004)$ & $1.5(0.02)$ \\
\hline Yes & 314 & & 282 & & \\
\hline No & 289 & & 144 & & \\
\hline Family history of osteoporosis & & $1.3(0.71)$ & & $0.3(0.09)$ & $0.6(0.29)$ \\
\hline Yes & 364 & & 55 & & \\
\hline No & 279 & & 172 & & \\
\hline Ever received corticosteroids & & $0.7(0.42)$ & & $1.8(0.08)$ & $1.2(0.57)$ \\
\hline Yes & 205 & & 301 & & \\
\hline No & 299 & & 164 & & \\
\hline Mobility & & $0.4(0.003)$ & & $1.3(0.38)$ & $0.8(0.24)$ \\
\hline Uses wheelchair & 221 & & 184 & & \\
\hline Walks with or without help & 523 & & 141 & & \\
\hline Type of wheelchair & & $0.9(0.74)$ & & $1.0(0.89)$ & $1.0(0.96)$ \\
\hline Manual & 216 & & 186 & & \\
\hline Electric-powered & 252 & & 178 & & \\
\hline Location of SCI & & $1.1(0.74)$ & & $2.4(<0.001)$ & $1.9(0.002)$ \\
\hline Lumbar & 251 & & 341 & & \\
\hline Cervical & 220 & & 141 & & \\
\hline Paresis & & $1.0(0.99)$ & & $1.3(0.21)$ & $1.2(0.31)$ \\
\hline Complete & 291 & & 206 & & \\
\hline Incomplete & 290 & & 154 & & \\
\hline Smoking status & & $1.4(0.34)$ & & $1.4(0.22)$ & $1.4(0.12)$ \\
\hline Ever smoker & 316 & & 191 & & \\
\hline Never smoker & 233 & & 139 & & \\
\hline Sports activities & & $1.1(0.73)$ & & $1.1(0.70)$ & $1.1(0.61)$ \\
\hline Yes & 300 & & 186 & & \\
\hline No & 272 & & 170 & & \\
\hline Use of standing device & & $0.6(0.14)$ & & $0.7(0.18)$ & $0.6(0.05)$ \\
\hline Yes & 179 & & 125 & & \\
\hline No & 317 & & 187 & & \\
\hline Crude rates & 282 & & 175 & & $1.6(0.008)$ \\
\hline
\end{tabular}

Numbers in brackets are $P$ values (Mantel-Haenszel $\chi^{2}$ )

continued to decrease during the observation period which could explain the observation ${ }^{8}$ that femoral fracture risk continued to increase with age and thus also probably with increasing time from the SCI. Furthermore, Biering-Sørensen et al observed that $\mathrm{BMC}$ of the forearms and lumbar spine remained stable during the observation period in accordance with our finding that vertebral fracture rates did not deviate from those observed in the general population and that forearm fractures were absent in the SCI patients. The sex distribution in our study $(71 \%$ males) did not deviate significantly from that reported by Biering-Sørensen et $a l^{20}$ for Denmark in the period $1974-1984$ for all SCI patients $(73 \%$ males, $P=0.45)$ and neither did the distribution of levels of SCI (in our study: cervical: $46 \%$, throacic: $32 \%$ and lumbar: $21 \%$ vs: $51 / 28 / 21 \%$ in traumatic SCI in Denmark, $P=0.45$ ). Our study group thus seems to be representative of
Danish SCI patients despite the fact that the questionnaire was mailed to members of a patient association.

Conclusion: fracture rates are significantly increased in SCI patients especially leading to low-energy fractures of the lower extremities and increases from the time of the injury to a stable level from the third year onwards. It also seems that the forearms are protected from fractures and that no specific factor except for female gender is consistently associated with an increased fracture risk.

\section{Acknowledgements}

We are indebted to the Danish Paraplegic Association for help and assistance with the questionnaires. We are also indebted to Mrs Birthe Gosvig Christensen, Mrs Lisbeth 
Rosenvinge Jensen and Mrs Jette Lind Thomsen and to the participants without the help of whom the making of this project would not have been possible.

\section{References}

1 Biering-Sørensen F, Bohr HH, Schaadt OP. Longitudinal study of bone mineral content in the lumbar spine, the forearm and the lower extremities after spinal cord injury. Eur J Clin Invest 1990; 20: $330-335$.

2 Biering-Sørensen F, Bohr H, Schaadt O. Bone mineral content of the lumbar spine and lower extremities years after spinal cord lesion. Paraplegia 1988; 26: 293 - 301.

3 Chantraine A, Nusgens B, Lapiere CM. Bone remodeling during the development of osteoporosis in paraplegia. Calcif Tissue Int 1986;38: 323 - 327

4 del Puente et al. Determinants of bone mineral density in immobilization: A study on hemiplegic patients. Osteoporosis Int 1996; 6: $50-54$.

5 Finsen V, Indradavik B, Fougner KJ. Bone mineral and hormone status in paraplegics. Paraplegia 1992; 30: $343-347$.

6 Comarr AE, Hutchinson RH, Bors E. Extremity fractures of patients with spinal cord injuries. Am J Surg 1962; 103: 732 - 739 .

7 Eichenholtz SN. Management of long-bone fractures in paraplegic patients. J Bone Joint Surg 1963; 45: 299-310.

8 Frisbie JH. Fractures after myelopathy: The risk quantified. $J$ Spinal Cord Med 1997; 20 66-69.

9 Ingram RR, Suman RK, Freeman PA. Lower limb fractures in the chronic spinal cord injured patient. Paraplegia 1989; 27: $133-139$.
10 Ragnarsson KT, Sell GH. Lower extremity fractures after spinal cord injury: a retrospective study. Arch phys med rehabil 1981; 62: $418-423$

11 Keating JF, Kerr M, Delargy M. Minimal trauma causing fractures in patients with spinal cord injury. Disabil Rehabil 1992; 14: $108-109$

12 Robin GC. Fracture in childhood paraplegia. Paraplegia 1997; 3: $165-170$.

13 Sobel M, Lyden JP. Long bone fracture in a spinal-cord injured patient: Complication of treatment - A case report and review of the literature. J Trauma 1991; 31: 1440-1444.

$14 \mathrm{Katz}$ JF. Spontaneous fractures in paraplegic children. $J$ Bone Joint Surg 1953; 35: 220-226.

15 Nottage WM. A review of long-bone fractures in patients with spinal cord injuries. Clin Orthop 1981; 65-70.

16 Kirby RL et al. Wheelchair-related accidents caused by tips and falls among noninstitutionalized users of manually propelled wheelchairs in Nova Scotia. Am J Phys Med Rehabil 1994; 73: $319-330$.

17 Goemaere S, Van Laere M, De Neve P, Kaufman JM. Bone mineral status in paraplegic patients who do or do not perform standing. Osteoporosis Int 1994; 4: $138-143$.

18 Melton III LJ. Epidemiology of fractures. In: Riggs BL, Melton III LF, (eds.) Osteoporosis: Etiology, diagnosis and management. Philadelphia: Lippincott-Raven, 1995; pp 225-247.

19 Cummings SR et al. Risk factors for hip fracture in white women. Study of Osteoporotic Fractures Research Group. N Engl J Med 1995; 332: $767-773$.

20 Biering-Sørensen F, Pedersen V, Clausen S. Epidemiology of spinal cord lesions in Denmark. Paraplegia 1990; 28: 105-118. 